http://nv.nltu.edu.ua

https://doi.org/10.15421/40290122

$@ \bowtie$ Correspondence author

Article received 21.01.2019 p.

Article accepted 28.02.2019 p.

I. B. Pirko

УДК 535.343.2

pirko1966@ukr.net

\author{
З. П. Чорнійच , В. М. Салапак', І. Б. Пірко1, Л. В. Салапак', А. Д. Кульчицький² \\ ${ }^{I}$ Начіональний лісотехнічний університет Украйни, м. Львів, Украӥна \\ ${ }^{2}$ Українська академія друкарства, м. Львів, Україна
}

\title{
РАДІАЦІЙНА ЧУТЛИВІСТЬ ІОННИХ КРИСТАЛІВ. ОДНОВИМІРНА МОДЕЛЬ. КРИСТАЛИ З ДЕФЕКТАМИ ДИПОЛЬНОГО ТИПУ
}

Виникнення радіаційного забарвлення в іонних кристалах є результатом локалізації створених радіацією вільних носіїв заряду на дорадіаційних точкових дефектах кристалічної гратки. Із накопиченням у кристалах центрів забарвлення вступають в дію зворотні процеси. Вільні носії заряду рекомбінують на центрах забарвлення, дорадіаційні дефекти відновлюються. Завдяки довготривалого опромінення кристалів встановлюється динамічна рівновага між процесами генерації центрів забарвлення та висвітлювальною дією рентгенівських променів. Запропоновано одновимірну модель іонних кристалів, у якій було розраховано параметри радіаційної чутливості кристалів флюоритів, легованих неізовалентними домішками. Імовірність генерації центрів забарвлення при розпаді електронно-діркової пари та імовірність висвітлювальної дії знижується зі зменшенням концентрації активатора. За високих температур незалежно від концентрації активатора в кристалі імовірність утворення центрів забарвлення під час розпаду електронно-діркової пари така ж, як імовірність їх руйнування. Це пояснено тим, що в обох випадках носії заряду взаємодіють із електронейтральними дипольними центрами. Зі зменшенням концентрації активатора зростає величина енергії, що витрачається на створення однієї комплементарної пари центрів забарвлення, а відповідно радіаційна чутливість кристала знижується.

Ключові слова: кристали; центри забарвлення; радіація.

Вступ. Представлена робота продовжує публікації (Chornij, et al., 2017), метою яких є систематизація радіаційних властивостей іонних кристалів залежно від їх структури, типу дефектів, концентрації та електричного заряду. У роботі (Chornij, et al., 2017) ми розрахували радіаційні характеристики кристалів зі зарядженими точковими структурними дефектами. У цій роботі дослідили кристали, що містять домішково-вакансійні диполі. Як об'єкти досліджень, вибрали кристали флюоритів, леговані лужними металами і радіаційні властивості яких інтенсивно досліджували впродовж п'яти останніх десятиріч (Stounkhem, 1978; Hayes \& Stoneham, 1974).

1. Структурні дефекти в кристалах флюоритів, легованих лужними металами. Іони лужних металів входять у гратку кристала у вигляді іонів заміщення (Chornii, et al., 1982). Надлишковий негативний електричний заряд лужних металів компенсує позитивно заряджена аніонна вакансія. За низьких температур аніонна вакансія розміщена в околі домішкового іона (локальний спосіб компенсації електричного заряду), утворюючи домішково-вакансійні диполі (ДВД) типу типу $\ominus+(\ominus$ - іон лужного металу, + - аніонна вакан- сія). Згідно з результатами досліджень струмів термостимульованої деполяризації (ТСД) (Chornii, et al., 1982):

- при Т < 120 К ДВД нерухомі в гратці кристала;

- у діапазоні температур $120 \mathrm{~K}<\mathrm{T}<370 \mathrm{~K}$ аніонна вакансія здійснює перепади за вісьмома еквівалентними позиціями аніона, які оточують лужний іон, тобто має місце ротація аніонної вакансії без ії відходу від домішкового іона;

- при Т > 370 К наступає термодисоціація ДВД: відбувається перехід від локального до просторового способу компенсації електричного заряду:

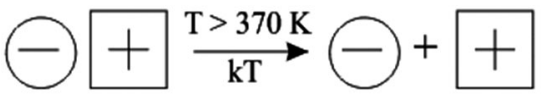

За цих температур іони лужних металів нерухомі в гратці кристала, а аніонні вакансії мігрують по гратці.

2. Механізм забарвлення кристалів. Структура центрів забарвлення. Як показують експериментальні результати, під час радіаційного опромінення кристалів флюоритів, легованих лужними металами, концентрація ДВД у кристалі зменшується (радіаційне руйнування ДВД), а відповідно концентрація центрів забарвлення зростас. Радіаційне руйнування ДВД і синхронне збільшення концентрації центрів забарвлення є результатом локалізації створених радіацією носіїв заряду на

Інформація про авторів:

Чорній Зеновій Павлович, д-р фіз.-мат. наук, професор, кафедра фізики.

Салапак Володимир Михайлович, канд. фіз.-мат. наук, доцент, кафедра фізики і математики.

Email: volodymyr.salapak@gmail.com

Пірко Irop Богданович, канд. фіз.-мат. наук, доцент, кафедри інформаційних технологій. Email: pirko1966@ukr.net

Салапак Любов Василівна, ст. викладач, кафедра технології матеріалів та машинобудування. Email: salapak@gmail.com

Кульчицький Антоній Дмитрович, канд. фіз.-мат. наук, доцент, кафедра фізики і математики. Email: kulchitskij@gmail.com

Цитування за ДСтУ: Чорній 3. П., Салапак В. М., Пірко І. Б., Салапак Л. В., Кульчицький А. Д. Радіаційна чутливість іонних кристалів. Одновимірна модель. Кристали з дефектами дипольного типу. Науковий вісник НЛТУ України. 2019, т. 29, № 1. С. $102-105$.

Citation APA: Chornij, Z. P., Salapak, V. M.., Pirko, I. B., Kulchitskiy, I. D., \& Salapak, L. V. (2019). Radiation Sensitivity of lonic Crystals. One-Dimensional Model. Crystals with Defects of Dipole Type. Scientific Bulletin of UNFU, 29(1), 102-105.

https://doi.org/10.15421/40290122 
ДВД: $\bigcirc+\cdots \mathrm{R}\left(\mathrm{e}^{-}, \mathrm{e}\right) \cdots \ominus+\mathrm{C} \rightarrow \longrightarrow+(1)$

У реакції, що описується рівнянням (1), зображено фрагмент іонного ланцюга, довжину якого обмежують ДВД $(\odot+$-диполь); крапками (...) позначені іони основи кристала; $\square$ - F-центр; $\odot \square$ - F центр, розташований в околі домішкового іона $($ );

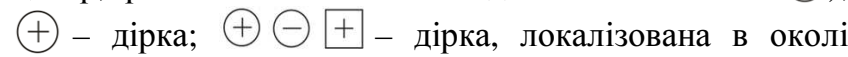
$\Theta+$-диполя; $\mathrm{V}_{\mathrm{KD}}$-центр - дірка, локалізована в околі диполя (інше позначення діркового центра - $\mathrm{V}_{\mathrm{KA}}(1)$; $\mathrm{V}_{\mathrm{KA}}$ - дірка, локалізована в околі домішкового іона (†) - дірка, (1) означає, що в околі центра знаходиться одна вакансія.

3 реакції (1) випливає, що внаслідок руйнування радіацією пари ДВД виникає комплементарна пара $\left(\mathrm{F}_{\mathrm{A}^{-}}\right.$ $\left.\mathrm{V}_{\mathrm{KA}}(1)\right)$-центрів забарвлення. $\left(\mathrm{F}_{\mathrm{A}}-\mathrm{V}_{\mathrm{KA}}(1)\right)$-центри забарвлення спостерігаємо в кристалі лише за Т < 200 К. Якщо кристал прогріти вище $200 \mathrm{~K}$, то $\mathrm{F}_{\mathrm{A}^{-}} \mathrm{i} \mathrm{V}_{\mathrm{KA}}(1)$-центри зникають і виникають $\mathrm{M}_{\mathrm{A}}{ }^{+} \mathrm{i} \mathrm{V}_{\mathrm{KA}}$-центри. Термоактивовані перетворення проходять за такою схемою:

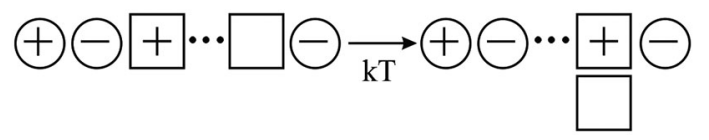

Реакція (2) проходить у два етапи. На першому етапі відбувається термоактивоване відщеплення аніонної вакансії від диполя 3 наступною міграцією іiі в гратці кристала:

$$
\text { (十) }
$$

тобто відбувається $\mathrm{V}_{\mathrm{KA}}(1) \rightarrow \mathrm{V}_{\mathrm{KA}}+\mathrm{V}_{a}$ перетворення. На другому етапі мобільна вакансія локалізується на $\mathrm{F}_{\mathrm{A}^{-}}$ центрі 3 наступним перетворенням $\mathrm{F}_{\mathrm{A}}(1)$-центра в $\mathrm{M}_{\mathrm{A}}{ }^{+}$центр:

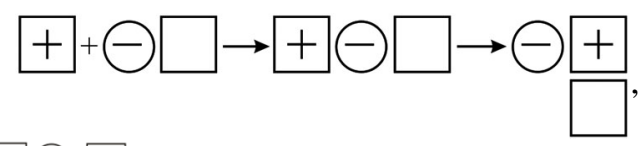

де: $\square \ominus+-\mathrm{F}_{\mathrm{A}}(1)$-центр (в околі FA-центра розташована одна вакансія); $\square+$ - M+-центр (бівакансія аніона локалізувала електрон); $\square \square-\mathrm{M}_{\mathrm{A}}+$-центр M+-центр, локалізований в околі іона лужного металу.

Отже, рівняння (3) описує перетворення одновакансійного $\mathrm{F}_{\mathrm{A}}$-центра в бівакансійний $\mathrm{M}_{\mathrm{A}}{ }^{+}$-центр: $\mathrm{V}_{\mathrm{a}}^{+}+\mathrm{F}_{\mathrm{A}}$ $\rightarrow \mathrm{F}_{\mathrm{A}}(1) \rightarrow \mathrm{M}_{\mathrm{A}}^{+}$.

До опромінення кристал флюориту містить електронейтральні відносно гратки структурні дефекти дипольного типу. У процесі опромінення виникають електрично заряджені відносно гратки центри забарвлення $\left(\mathrm{F}_{\mathrm{A}^{-}}\right.$ $\left.\mathrm{V}_{\mathrm{KA}}(1)\right)$-комплексні пари. Отже, під час опромінення кристала відбувається радіостимульований перехід від локального способу компенсації електричного заряду до просторового, що збільшує енергію кристалічної гратки. У кристалах флюоритів під час утворення кожної пари центрів забарвлення енергія кристалічної гратки зростає на 1 еВ. Іонні процеси, що описуються рівнянням (3), зумовлюють перезарядку центрів забарвлення: пари електрично заряджених центрів $\left(\mathrm{F}_{\mathrm{A}^{-}}\right.$ $\left.\mathrm{V}_{\mathrm{KA}}(1)\right)$-центрів перетворюються в пари $\left(\mathrm{M}_{\mathrm{A}}^{+}-\mathrm{V}_{\mathrm{KA}}\right)$-центрів із дипольною структурою. Тобто локальний спосіб компенсації електричного заряду в гратці забарвленого кристала відновлюється - відбувається релаксація енергії забарвленого кристала.

3. Встановлення термодинамічної рівноваги між дорадіаційними дефектами та центрами забарвлення

3.1. Кристали, опромінені за Т < 200 К. Рівняння (1) описує механізм генерації центрів забарвлення під дією іонізуючої радіації. В міру нагромадження у кристалі центрів забарвлення вступає в дію механізм їх радіаційного руйнування (радіаційного висвітлення):

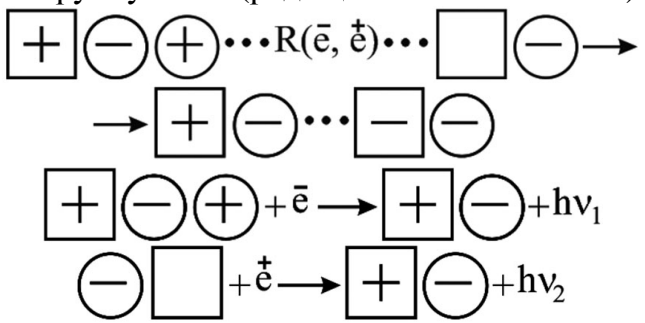

Зонні електрони рекомбінують на $\mathrm{V}_{\mathrm{KA}}(1)$-центрах (рівняння 6.1), а дірки - на $\mathrm{F}_{\mathrm{A}}$-центрах (рівняння 6.2). Внаслідок рекомбінаційних процесів центри забарвлення зникають, а ДВД- відновлюються. Рекомбінація супроводжується свіченням: $h v_{1}$ і $h v_{2}$ - енергії квантів світла, які утворюються за верхнього (рівняння 6.1) та нижнього (рівняння 6.2) механізмів рекомбінації.

Під час довготривалого опромінення кристала встановлюється динамічна рівновага між процесами генерації центрів забарвлення (рівняння 1) та їх радіаційної анігіляції (рівняння 5). У цьому випадку забарвлення кристала досягає насичення:

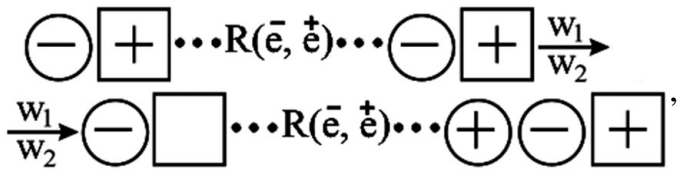

де: $w_{1}-$ імовірність утворення центрів забарвлення під час розпаду електронно-діркової пари у фрагменті іонного ланцюга (імовірність перебігу реакцій 1 ); $w_{2}$ - імовірність радіаційного руйнування пари центрів забарвлення (рівняння 5).

3.2. Кристали, опромінені за кімнатної температури. За кімнатної температури забарвлені кристали флюоритів містять $\left(\mathrm{M}_{\mathrm{A}}{ }^{+}-\mathrm{V}_{\mathrm{KA}}\right)$ комплементарні пари центрів забарвлення. Їхні висвітлення відбувається за схемою:

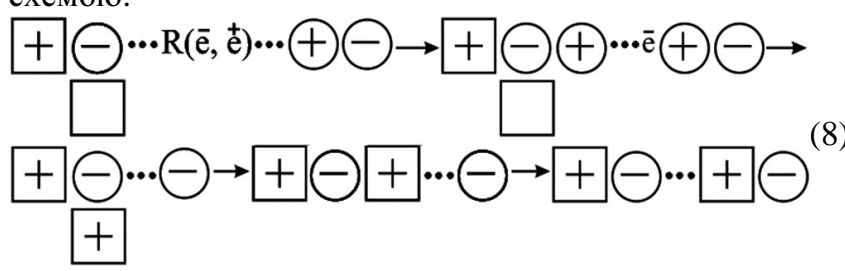

Процес радіаційного висвітлювання центрів забарвлення проходить у два етапи.

Перший етап. Внаслідок електронно-діркової рекомбінації центри забарвлення, що мають дипольну структуру, зникають і утворюються електрично заряджені структурні дефекти. Тобто завдяки електронно-дірковим процесам відбувається перехід від локальної електричної компенсації електричного заряду до просторового, що збільшило потенціальну енергію знебарвленого кристала, порівняно зі забарвленим кристалом (Chornii, et al., 1982).

На другому етапі внаслідок іонних процесів локальний спосіб компенсації електричного заряду дефектів відновлюється: 


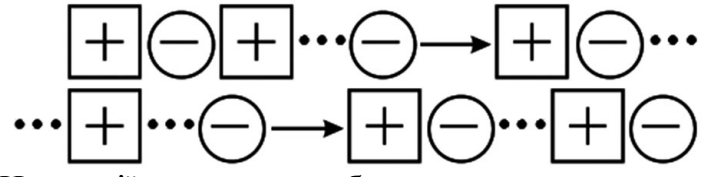

На стадії насичення забарвлення кристала динамічна рівновага, яка настає у кристалі за кімнатної температури, описуємо рівнянням:

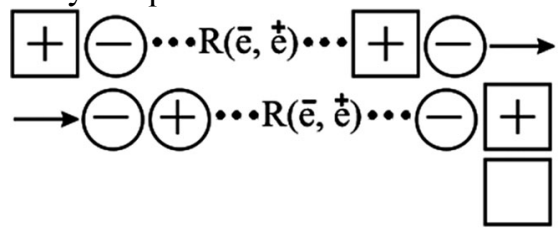

3 огляду на те, що як дорадіаційні дефекти, так i центри забарвлення мають структуру диполів, імовірність генерації центрів забарвлення $w_{1}$ збігається за величиною 3 імовірністю їх радіаційного висвітлювання $w_{2}\left(w_{1}=w_{2}\right)$.

Результати розрахунків радіаційних параметрів кристалів. Розрахунок радіаційних параметрів кристалів флюоритів, легованих лужними металами, проведено в одномірній моделі іонного кристала за методикою, яку описано в роботі (Chornii, et al., 2008). У цій моделі визначено: $w_{1}$ - імовірність утворення центрів забарвлення під час розпаду однієї електронно-діркової пари в кристалі; $w_{2}-$ імовірність радіаційного знебарвлення пари центрів забарвлення; $E$ - енергія, яка затрачається на створення пари центрів забарвлення.

$$
E=\frac{1,5}{w_{1}} E_{g},
$$

де: $E_{g}$ - ширина забороненої зони кристала; $c_{1}$ i $c_{2}-$ граничні концентрації центрів забарвлення (концентрація центрів забарвлення на стадії насичення забарвлення кристала) у кристалах, опромінених за низьких $\left(c_{1}\right)$ i кімнатної $\left(c_{2}\right)$ температур

$$
c_{1}=\frac{w_{1}}{w_{1}+w_{2}} c_{0}, c_{2}=\frac{1}{2} c_{0},
$$

де $c_{0}-$ початкова концентрація пар ДВД у кристалі до його опромінення.

Результати розрахунків наведено в таблиці і на рис. 1 та 2.

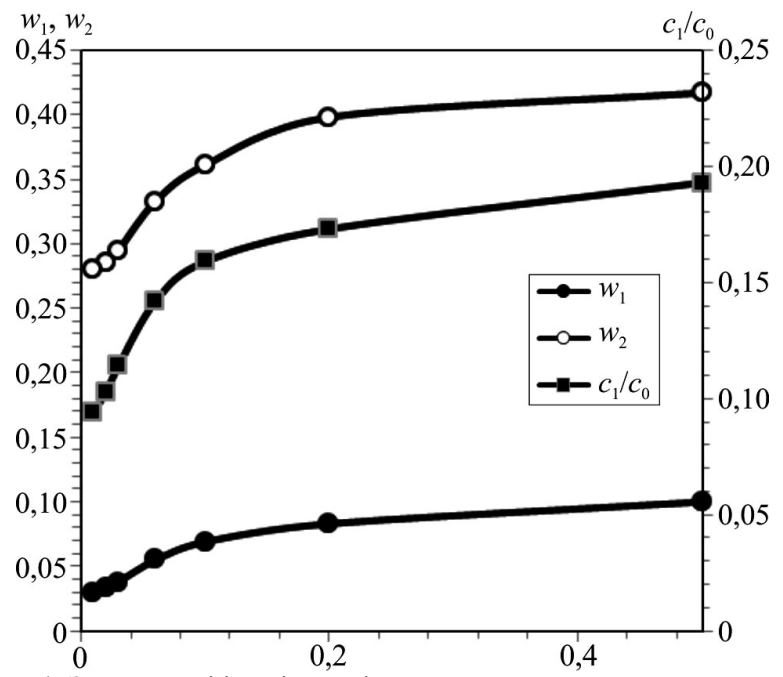

Рис. 1. Залежності імовірності утворення активаторної пари центрів забарвлення $\left(\mathrm{w}_{1}\right)$, імовірності зникнення активаторної пари центрів забарвлення $\left(\mathrm{w}_{2}\right)$, відношення граничної концентрації пар центрів забарвлення на стадії насичення забарвлення кристала до числа пар іонів домішки $\left(\mathrm{c}_{1} / \mathrm{c}_{0}\right)$ від концентрації с домішкових іонів

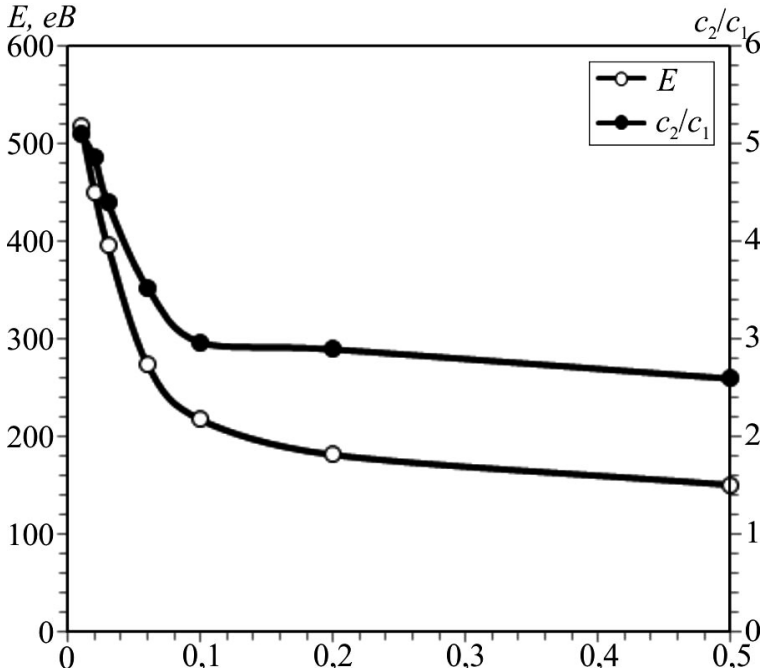

Рис. 2. Відношення граничної концентрації пар центрів забарвлення на стадії насичення забарвлення кристала за кімнатної температури до граничної концентрації пар центрів забарвлення на стадії насичення забарвлення кристала за низьких температур $\left(c_{2} / c_{1}\right)$ та енергії E, що затрачена на генерацію пари центрів забарвлення від концентрації з домішкових іонів.

Таблиця. Радіаційні параметри кристалів

\begin{tabular}{|c|c|c|c|c|c|c|c|}
\hline$c$ & $l$ & $w_{1}$ & $w_{2}$ & $c_{1} / c_{0}$ & $c_{2} / c_{0}$ & $E, \mathrm{eB}$ & $c_{2} / c_{1}$ \\
\hline 0,50 & $6 \mathrm{a}$ & 0,100 & 0,417 & 0,193 & 0,5 & 150 & 2,59 \\
\hline 0,20 & $8 \mathrm{a}$ & 0,083 & 0,398 & 0,173 & 0,5 & 181 & 2,89 \\
\hline 0,10 & $10 \mathrm{a}$ & 0,069 & 0,361 & 0,159 & 0,5 & 217 & 2,96 \\
\hline 0,06 & $12 \mathrm{a}$ & 0,055 & 0,333 & 0,142 & 0,5 & 273 & 3,52 \\
\hline 0,03 & $15 \mathrm{a}$ & 0,038 & 0,295 & 0,114 & 0,5 & 395 & 4,39 \\
\hline 0,02 & $17 \mathrm{a}$ & 0,033 & 0,285 & 0,103 & 0,5 & 450 & 4,85 \\
\hline 0,01 & $21 \mathrm{a}$ & 0,029 & 0,280 & 0,094 & 0,5 & 517 & 5,10 \\
\hline
\end{tabular}

\section{Висновки:}

1. Як видно 3 таблиці, імовірність $\mathrm{w}_{1}$ утворення центрів забарвлення під час розпаду електронно-діркової пари менша за імовірність $w_{2}$ висвітлювальної дії центрів забарвлення. Причина такої закономірності зумовлена тим, що монополь-дипольна взаємодія є набагато меншою за кулонівську взаємодію між вільними носіями заряду і центрами забарвлення. Отже, імовірність захоплення носіїв заряду ДВД $є$ меншою за імовірність їх рекомбінації на центрах забарвлення.

2 . Величини $w_{1}$ i $w_{2}$ зменшуються зі зниженням концентрації домішкових іонів, а відповідно зі збільшенням середньої відстані між домішково-вакансійними диполями (див. таблиця, рис. 1).

3. Оскільки енергія радіації, що затрачається на створення пари, $є$ функцією $\mathrm{E} \approx f(1 / w)$ (рівняння 11), то енергетичні затрати радіації на створення центрів забарвлення Е зростає зі зменшенням вмісту домішки в кристалі (див. рис. 2)

4. Результати розрахунків показують, що на стадії насичення забарвлення кристала гранична концентрація $\mathrm{F}_{\mathrm{A}}$ центрів досягає 10-20\% від концентрації активатора, а концентрація $\mathrm{M}_{\mathrm{A}}{ }^{+}$-центрів досягає $50 \%$.

5. Величина радіаційного забарвлення кристалів у декілька разів вища в кристалах, опромінених за кімнатної температури $-\mathrm{c}_{2}$, порівняно із кристалами, опроміненими за низьких температур - $c_{1}$ (див. рис. 2). Така закономірність зумовлена зміною зарядового стану центрів забарвлення. За низьких температур у кристалах утворюються електрично заряджені центри забарвлення $\left(\mathrm{F}_{\mathrm{A}}-\mathrm{V}_{\mathrm{KA}}(1)\right)$-пари, а за кімнатної - центри забарвлення дипольного типу $\left(\mathrm{M}_{\mathrm{A}}{ }^{+}-\mathrm{V}_{\mathrm{KA}}\right)$, що зумовлює зменшення висвітлювальної дії рентгенівських променів. 


\section{Перелік використаних джерел}

Chornii, Z. P., Panasiuk, M. R., Krochuk, A. S., Maksimovich, Kh. K., \& Shhur, G. A. (1982). Vliianie fotokhimicheskoi okraski na termostimulirovannye toki depoliarizatcii v kristallakh $\mathrm{SrCl}_{2}-\mathrm{K}$. Ukrainskii fizicheskii zhurnal, 27(8), 1219-1223. [In Russian].

Chornii, Z. P., Pirko, I. B., Salapak, V. M., \& Diachuk, M. V. (2008). Modeliuvannia radiatsiinykh vlastyvostei ionnykh krystaliv. Scientific Bulletin of UNFU, 18(1), 220-226. [In Ukrainian].
Chornij, Z. P., Salapak, V. M., Pirko, I. B., Salapak, L. V., \& Kulchytskiy, A. D. (2017). Radiation sensitivity of ionic crystals. One-dimension model. I. Ionic crystals, doped with isovalent impurities. Scientific Bulletin of UNFU, 27(10), 92-95. https://doi.org/10.15421/40271017

Hayes, W., \& Stoneham, A. M. (1974). Crystals with fluorite structure. W. Oxford, $448 \mathrm{r}$.

Stounkhem, A. N. (1978). Teoriia defektov v tverdykh telakh. (Vol. 2). Moscow, 357 p. [In Russian].

Z. P. Chornij 1, V. M. Salapak ${ }^{1}$, I. B. Pirko' ${ }^{1}$, L. V. Salapak ${ }^{1}$, I. D. Kulchitskiy ${ }^{2}$

${ }^{1}$ Ukrainian National Forestry University, Lviv, Ukraine

${ }^{2}$ Ukrainian Academy of Printing, Lviv, Ukraine

\section{RADIATION SENSITIVITY OF IONIC CRYSTALS. ONE-DIMENSIONAL MODEL.} CRYSTALS WITH DEFECTS OF DIPOLE TYPE

The occurrence of the radiation color in ionic crystals is the result of the localization of free charge carriers, generated by radiation, on the pre-radiation point defects of the crystalline lattice. With the accumulation of the color centers in the crystals, inverse processes take effect. The free charge carriers recombine at the color centers, and the pre-radiation defects are restored. Prolonged irradiation of the crystals establishes a dynamic equilibrium between the processes of generation of color centers and the illumination effect of X-rays. A one-dimensional model of ionic crystals was proposed, in which calculated were the parameters of radiation sensitivity of fluorite crystals doped with non-isovalent impurities. It is found that at low temperatures regardless of the concentration of the activator in the crystal, the probability of the formation of color centers at the decay of electron-hole pairs is always less than the probability of their destruction. This is explained by the fact that in the first case, the charge carriers interact with electroneutral dipole centers, while in the second case - with charged ones. The probability of the generation of color centers at the decay of the electronhole pair and the probability of the illumination effect decrease with decreasing concentrations of the activator in the crystal. It is found that at high temperatures regardless of the concentration of the activator in the crystal, the probability of the formation of color centers at the decay of electron-hole pairs is always the same the probability of their destruction. This is explained by the fact that in both cases, the charge carriers interact with electroneutral dipole centers. As the concentration of the activator decreases, the amount of energy consumed to create one complementary pair of color centers increases, and, accordingly, the radiation sensitivity of the crystal drops. As shown by the theoretical calculations, within the framework of this model, boundary concentrations of color centers are determined depending on the concentration of the impurity.

Keywords: crystals; color centers; radiation. 